\title{
Rainwater Resources Development using Open Space data and Software Sources
}

\author{
(A study case: Damazin locality, Blue Nile state, Sudan) \\ Gar Al-nabi Ibrahim Mohamed ${ }^{\#}$ and Faisal Althobiani ${ }^{\wedge}$ \\ \#Hydrographic Surveying Department, ^Department of Marine Engineering, Faculty of Maritime Studies, King Abdulaziz University, KSA \\ Received 08 Aug 2018, Accepted 11 Oct 2018, Available online 13 Oct 2018, Vol.6 (Sept/Oct 2018 issue)
}

\begin{abstract}
Humans and animals drinking water availability is a chronic problem in under-developed countries in general and their rural areas in particular. A rainwater resources development effort was reported in this paper using a case study area in the Sudan. A rainwater harvesting method was developed using open space technology data and open application programs. The method was applied in a 12,100 square kilometers area and twenty-two potential rainwater harvesting sites were located with draining capacities ranging between 19.10 and 532.50 Million Cubic Meters (MCM) with a total average rainfall rate draining capacity of 2.105 Billion Cubic Meter (BCM). However, although it is quite possible to acquire this huge amount of water in the area, but unfortunately, local people are still facing a chronic problem of drinking water shortage, animals walk tens of kilometers to drink water and farmers transport water from the Blue Nile river tens of kilometers away from the farms to harvest their crops. An appreciated effort was made by local governments and non-government organizations related to drinking water world wide in general and in underdeveloped countries in particular using traditional methods. However, it is high time to devote this effort to the application of open space technology data and open application programs for water harvesting in these areas. This would facilitate the water supply throughout the year and avoid the drinking water shortage in the dry season. It can be applied to cover the whole area with a network of water harvesting facilities to achieve nomad's and pastoralists settlement, avoid their conflicts with farmers in the area.
\end{abstract}

Keywords: Hafeer, rainwater resource, potential rainwater harvesting site, open space data source, open application programs source, Water harvesting facility, rate of rainfall

\section{Introduction}

Water is very important for humans as well as animals and most of the natural resources disputes in the world are related to water.

"Sudan rainfall decreases northwards $(0-700 \mathrm{~mm})$, with a total annual amount of 400 billion $\mathrm{m}^{3}$ "[2]. "Sudan estimated annual rainfall is 442 BCM. The most abundant water resource is rainfall. Harnessing rainwater and floods is not widely practiced and water harvesting is poorly developed. Although the practice is old, it is only carried out on a small scale [1]. Rainfall collection is one of water sources in Sudan and rainwater harvesting (RWH) methods can be implemented to improve the production of crops and livestock in the region [3]

The quoted texts demonstrated that the Sudan rainfall water resources are very good, but are not exploited for

*Corresponding author's ORCID ID: 0000-0003-4655-6736 DOI: https://doi.org/10.14741/ijmcr/v.6.5.12 the benefits of the Sudanese people in general and in the rural areas in particular. This paper investigated the potentialities of open space technology data and open application programs in rainwater resources development. The space technology data and application programs were integrated to derive the hydrographical and hydrological models of the study area. The two models were integrated to derive the draining water areas and their relative geometric data.

\section{Study area}

The study area is located west of the Blue Nile in Damazin locality, Blue Nile state Sudan. It is bounded by latitudes $11^{\circ}$ and $12^{\circ} \mathrm{N}$ and longitudes $33.25^{\circ}$ and $34.5^{\circ} \mathrm{E}$. The approximate study area is $12,100 \mathrm{sq}$. $\mathrm{km}$. The main features in the area are the Blue Nile river, the rain-fed mechanized agricultural lands, and a series of mountains, forming a water divide zone and a large number of villages scattered all over the area (Fig. 1). 


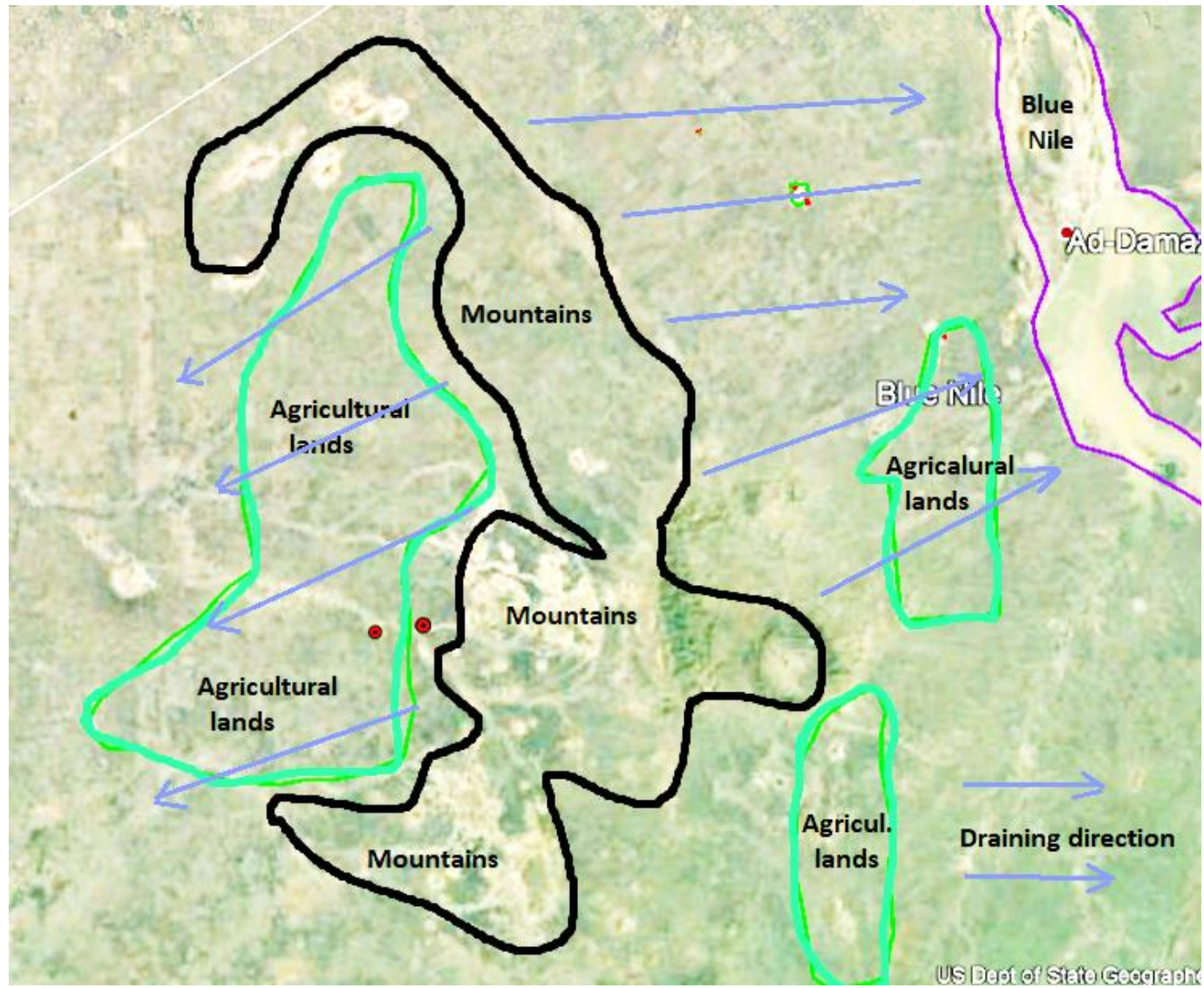

Figure 1 The geographical location of the area and its main features, Agriculture areas (bounded green), mountains (bounded black), sample villages (red circles), rainwater flow direction (blue arrow) and Blue Nile

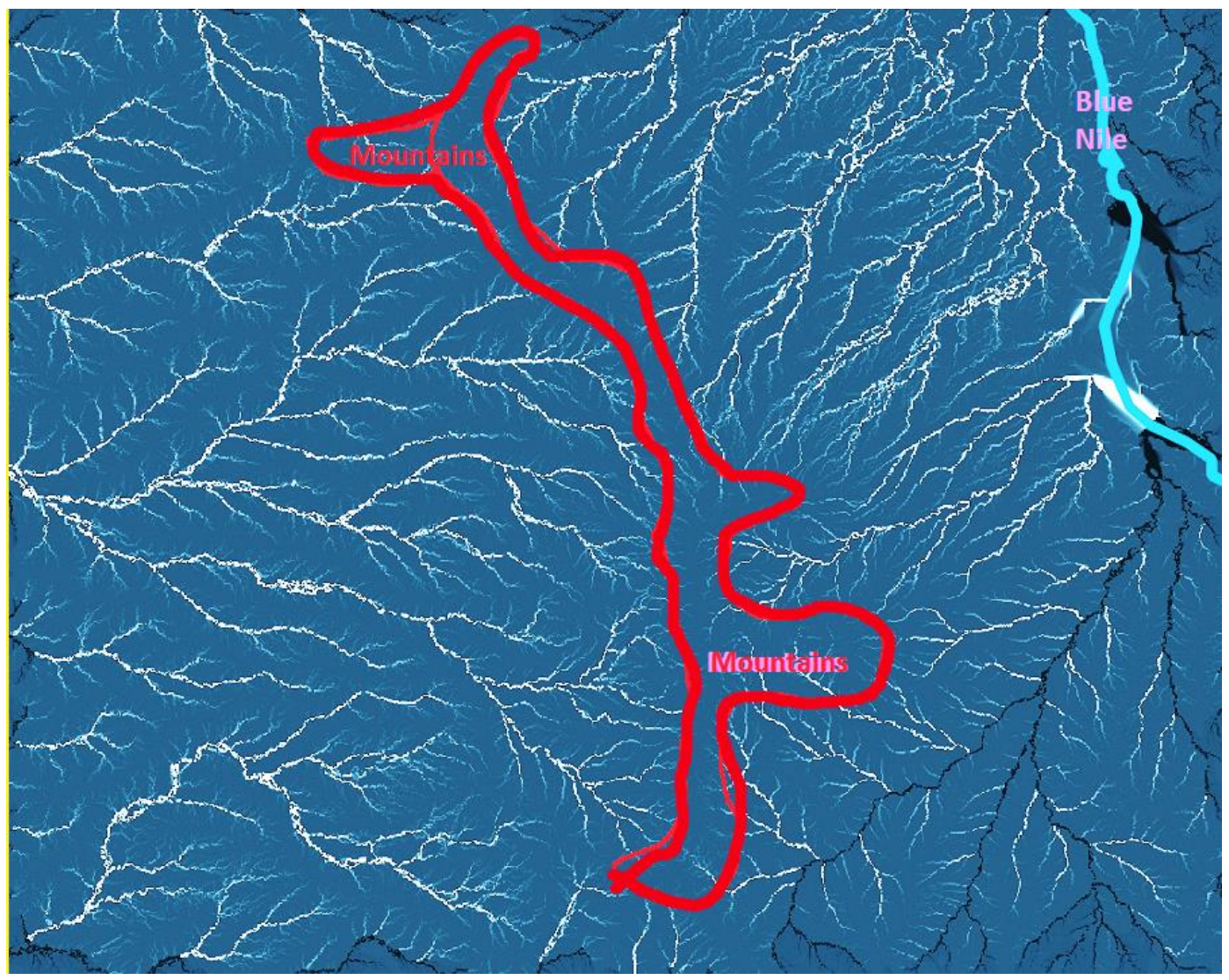

Figure 2 The drainage network in the study area 


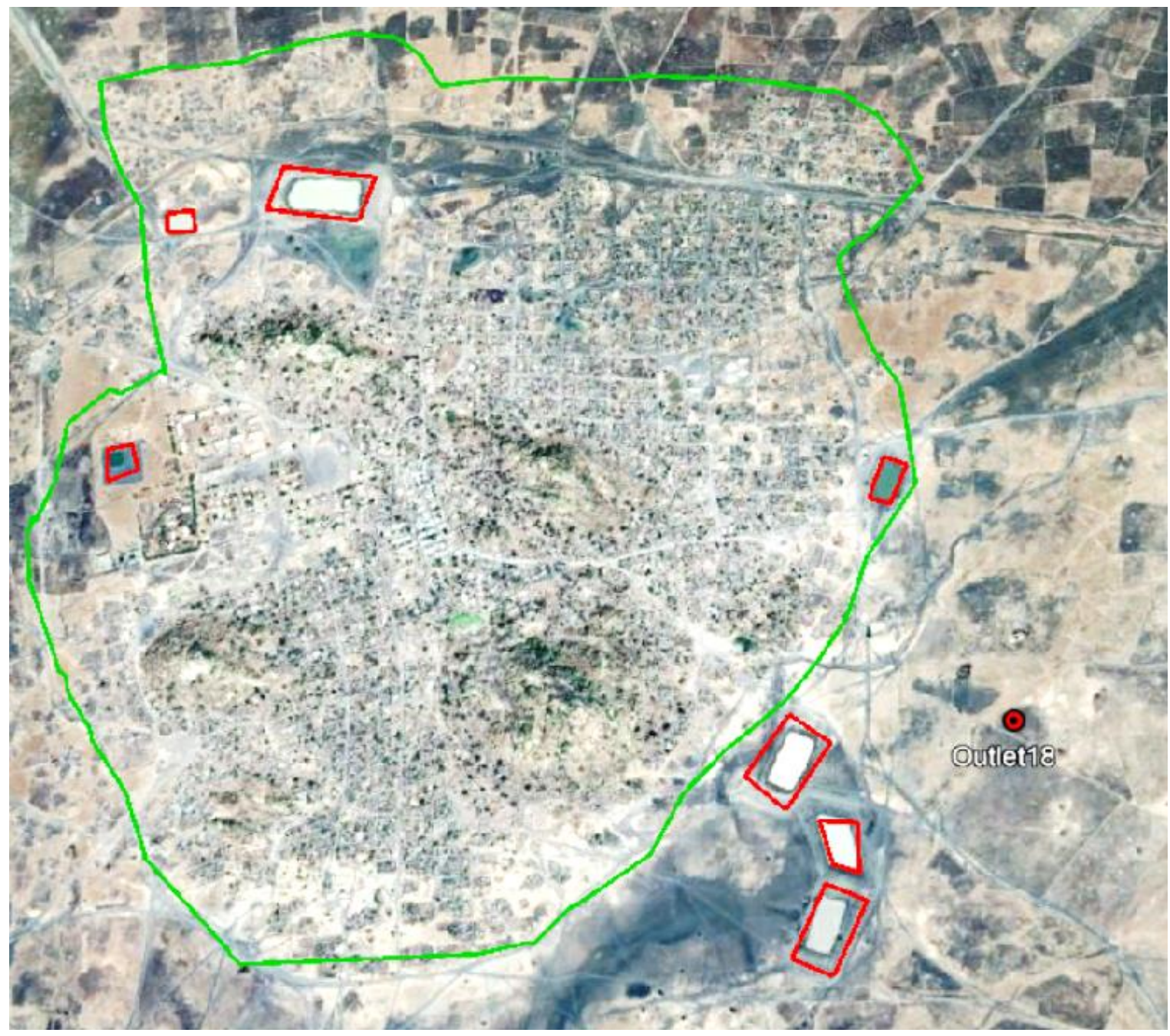

Figure 3 A typical example of a residential site surrounded by seven Hafeers and an $80 \mathrm{MCM}$ open space data and applications programs water harvesting site, only 500 m away

The study area is characterized by a high range of rainfall rate $(300-700 \mathrm{~mm})$, a long rainfall period that extends up to four months [4] and a very dense drainage network (Fig. 2). It is a livestock, crop and mining production area. Agriculture in the area is practiced through two methods, traditional small and modern mechanized rain-fed farming. Livestock is also, practiced through two methods, small local people traditional and large pastoral herder's sheep and cattle husbandry.

The rainfall water is the main available drinking water source for both humans and animals in the area for as the ground water is either not available or at very long depths in the ground [1]. It is harvested using traditional methods and stored in small reservoirs called Hafeers. The Hafeer is an earth embankment water storage with an average storage capacity of 200,000 Cubic Meters (CM). The location and construction of these Hafeers are based on the experience of the local people. Fig. 3 is a typical example of the water harvesting practice in the study area. It shows a residential area composed of two villages (Shaykh Idris and Elbrun, bounded blue), seven Hafeers (bounded red) and a potential water harvesting site (circular shape) 500 meters away from the residential area.

Fig. 3, clearly demonstrated that the local people and local authorities had made an excellent effort to provide water in the area, but their effort was based on the experience of the local people and a very limited local drainage network around the area. The reason for constructing this large number of Hafeers around this small residential site is twofold. Firstly, the Hafeer is not enough to supply the area with the required volume of water. Secondly, there is no grantee that the Hafeer location catchment area is sufficient for supplying the required volume of water as the latter is a function of the rainfall rate for the year. Accordingly, the provision of the water volume required to supply the area through out the year should be made by increasing the storage volume and constructing the storage facility in a location with a catchment area sufficient to supply the needed volume of water with the minimum rate of rainfall in the area.

\section{Objectives}

The objective of this research is to investigate the rainwater resources development potentialities using 
open space technology data and application programs sources. The effort made in the research was devoted towards the formation of the hydrological model of the area, the derivation of the potential water harvesting locations and their relative geometric information and evaluation of the results compared to those of the existing traditional water harvesting methods in the study area.

\section{Methodology}

The methodology adopted in this investigation was based on the formation of the hydrological model of the area and the derivation of its water harvesting parameters. These parameters comprise the location of the draining areas, their draining outlets and relative geometric information. This was achieved by downloading the digital elevation model (SRTM90) [5] of the area and processing it using the free of charge QGIS application software [6]. In addition, the free of charge Google Earth application program was adopted to locate the geographical location of the study area its main topographical features and typical examples of the traditional water harvesting methods.

\section{Data processing and results}

Google Earth on-line GIS facilities were used to locate the study area, identify its main topographical features and locate typical examples of the traditional water harvesting sites (Hafeers) in the residential and agricultural areas. The digital (SRTM90) elevation model of the study area was downloaded and processed and the hydrological model of the area was derived using QGIS hydrological application modules. The model accumulation raster was used to locate the potential water harvesting sites in the area and their geometric information was derived.

The research results are presented in Fig. 4, which shows the open space data and application programs sources potential water harvesting sites in the study area and their relative catchment areas. These areas ranged between 064 to $1775 \mathrm{~km}^{2}$. This is equivalent to a range of 19.10 to $532.50 \mathrm{MCM}$ of average rainfall rate draining volume of water. The outlets falling inside the draining areas represent sub draining areas.

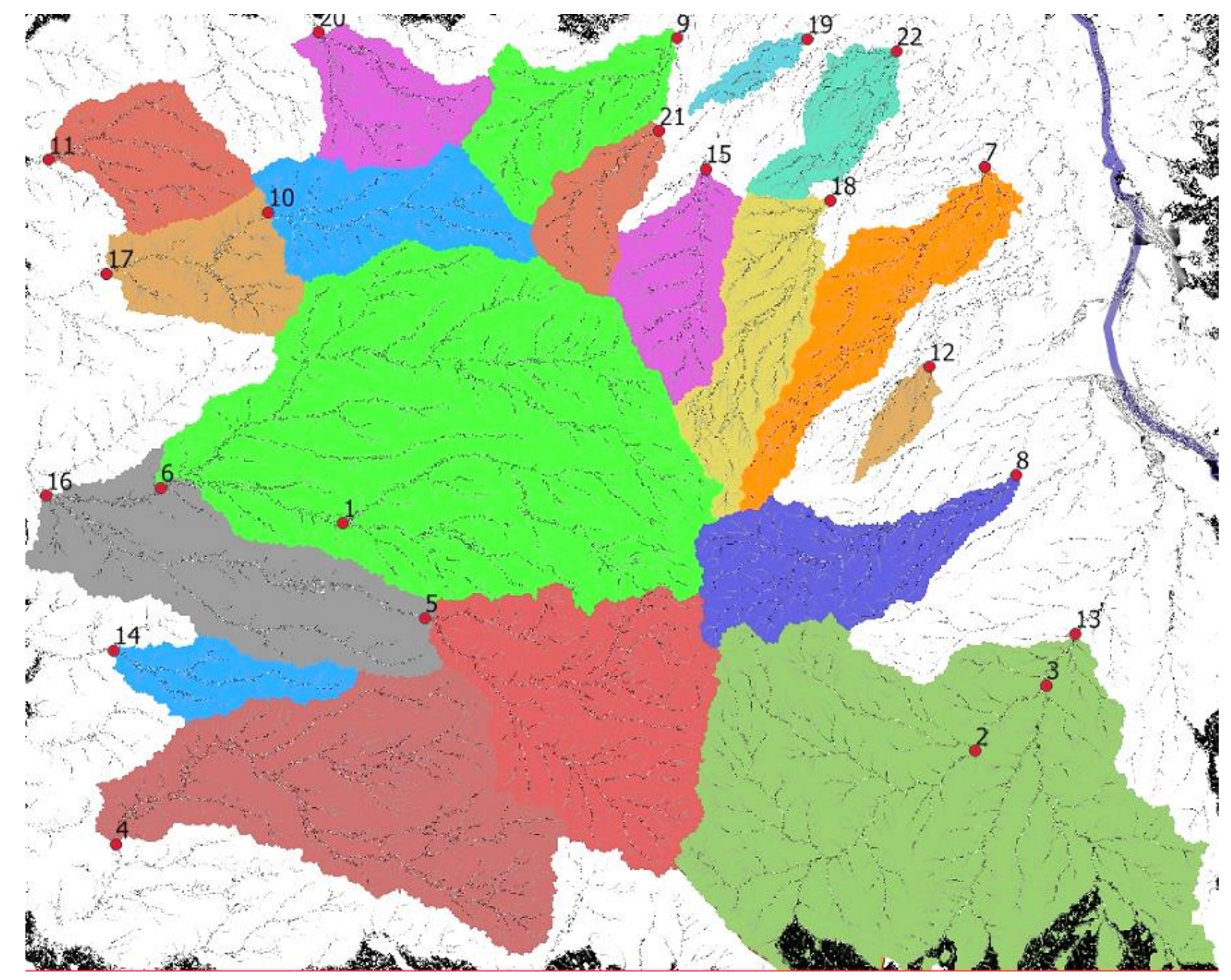

Figure 4 The hydrological model of the study area showing the main draining areas (Colored Zones) and outlets (red circles) 


\section{Discussion}

Fig. 4 clearly revealed that it is quite possible to harvest a huge volume of water from the study area (2.105 Million Cubic Meters) using the open space technology data and application programs sources. Twenty-two potential water harvesting sites were identified with average rainfall rate water volumes that range between 19.10 to $532.50 \mathrm{MCM}$. This demonstrated the advantages of the reported approach over the traditional water harvesting methods. This approach facilitates the determination of the whole catchment area of the water harvesting location. It allows the integration of the catchment area, the rate of rainfall and the required volume of water and thus grantees the annual supply of the required volume of water. Moreover, the demonstrated approach minimizes the cost and effort for establishing the water harvesting facilities in the area. A typical example of this is demonstrated in Fig. 3, where seven Hafeers were constructed in a residential area with small number of population (10,000 approximately). The investigation located a potential water harvesting site of $80.1 \mathrm{MCM}$ only, 500 meters from the village. Accordingly, if only $50 \%$ of this volume of water is harvested (precipitation and evaporation) it would be quite enough to supply the residential area with drinking water for both humans and animals throughout the year. This clearly revealed the possibility of constructing only one water harvesting facility (Hafeer/dam) and the required annual volume of water would be provided with the minimum rate of rainfall in the area.

Another typical example in the agricultural area is demonstrated by Fig. 5, which shows some water harvesting facilities (Hafeers) inside the agricultural area with storage capacity of 150,000 cubic meters and a potential water harvesting site with drainage capacity 9.9 MCM (site 12), two kilometers away from them. In fact, these Hafeers are constructed by farmers to provide water for the workers but they become dry soon after the rainy season is over. This is exactly the crop harvesting time where farmers are in desperate need of water and forced to transport it from the Blue Nile river tens of kilometers away. Again, if the reported approach is applied it would enable the farmers to construct their water collection facility (Hafeer/Dam) inside the farms area and have water supply throughout the year. However, some of the farmers need to transport water to their farms but this is far better compared to transporting it from the Blue Nile river. Another alternative is to train some of the drainage network branches in the vicinity of the water harvesting site to create a small storage facility for each farm.

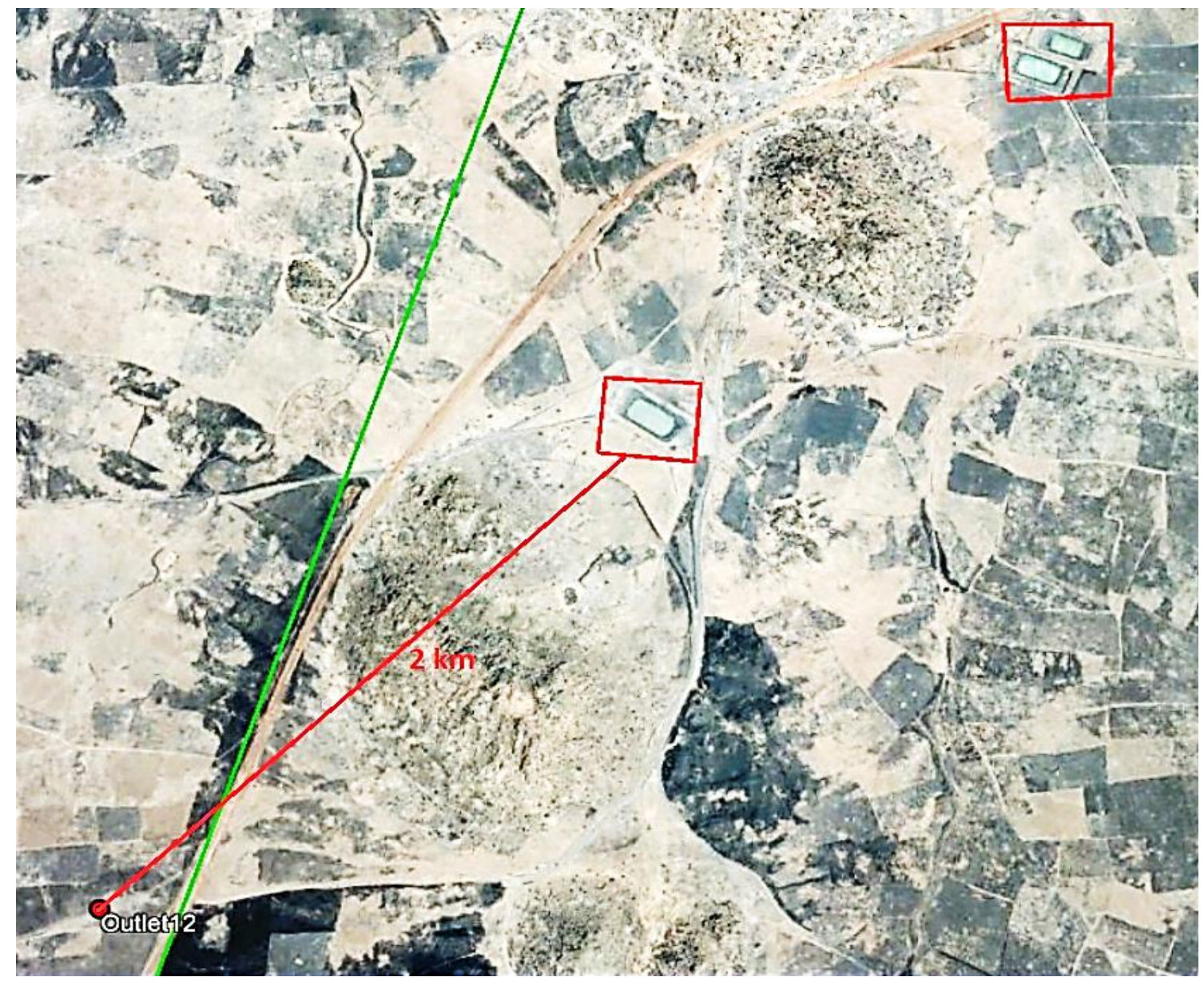

Figures 5 Typical water harvesting facilities (Hafeers) inside the agricultural area (red boxes) and a potential water harvesting site 9.9 MCM (red circle) 


\section{Conclusions}

The effort made in the investigation clearly demonstrated the potentialities of rainwater resources development using open space technology data and application programs sources. This developed approach has many advantages compared to the traditional ones. The water harvesting site can be located based on the required volume of water and the minimum rate of rainfall. This facilitates the supply of drinking water throughout the year, improve the living standard of the local people in the area. The efficiency of the technique facilitates the coverage of the area with a regular network of water collection facilities and the settlement of nomads and pastoralists to avoid their conflicts with farmers as the formers pass through farms with their animals to reach the Blue Nile. The negative environmental impacts will be decreased by the increase of the green areas.
A detailed survey of the potential water harvesting site can be made to determine the best water storage facility location. The best facilities are the natural depressions (Torda, Rahad, Fola). However, Hafeers and dams with different storage capacities can well be constructed to serve the purpose.

\section{References}

[1]. https://water.fanack.com/sudan/water-resources-sudan/ (Accessed Sep. 2018)

[2]. http://www.oicvet.org/Presentations/Water_Management _Symposium/Sudan/Sudan.pdf (Accessed Sep., 2018)

[3]. https://ascelibrary.org/doi/abs/10.1061/41036\%28342\%29 230 (Accessed Sep, 2018)

[4]. https://www.researchgate.net/publication/275016737_Wa ter_Resources_in_Sudan (Accessed Sep, 2018)

[5]. Shuttle Radar Topography Mission (SRTM), internet site http://www.cgiar-csi.org/data/srtm-90m-digital-elevationdatabase-v4-1 (Accessed Sep, 2018)

[6]. https://earth.google.com/download-earth.html (Accessed Sep, 2018) 